\section{LAS PERIODISTAS ESPAÑOLAS PINTADAS POR SÍ MISMAS}

\author{
Ángeles Ezama Gil \\ Universidad de Zaragoza \\ aezama@unizar.es
}

\section{THE SPANISH WOMEN JOURNALISTS DEPICTED BY THEMSELVES}

Cómo citar este artículo/Citation: Ezama Gil, A. (2014). "Las periodistas españolas pintadas por sí mismas". Arbor, 190 (767): a136. doi: http://dx.doi.org/10.3989/ arbor.2014.767n3007

Recibido: 3 julio 2013. Aceptado: 6 abril 2014

RESUMEN: Cinco grandes periodistas españolas, que fueron colaboradoras, redactoras y directoras de revistas, abordaron en algunos de sus escritos y discursos la definición del status de la mujer periodista entre los siglos XIX y XX: Emilia Pardo Bazán, Concepción Gimeno, Carmen de Burgos (Colombine), Isabel Oyarzábal y Carmen Eva Nelken (Magda Donato). En todas ellas es común la idea de que la mujer posee cualidades innatas para el ejercicio del periodismo, y de que la prensa es una tribuna desde la que educar a sus congéneres del mismo sexo. Su periodismo se nutre de dos modelos primordiales, el decimonónico de la crónica, de origen francés, y los más modernos de la entrevista y el reportaje, de origen anglosajón. En el ejercicio periodístico las únicas limitaciones para las mujeres en España parecen ser la función de directora de periódico diario y el género del reportaje, ambos de sesgo claramente masculino, en tanto que a las mujeres están reservados géneros considerados más adecuados a su sexo como la crónica y la entrevista.

PALABRAS CLAVE: mujer periodista; reportaje; crónica; entrevista; Colombine; Magda Donato.
Copyright: (C) 2014 CSIC. Este es un artículo de acceso abierto distribuido bajo los términos de la licencia Creative Commons Attribution-Non Commercial (by-nc) Spain 3.0.

ABSTRACT: In some of their writings and speeches, five major Spanish journalists, who were also magazine contributors and editors, addressed the status of women journalists between the nineteenth and twentieth centuries: Emilia Pardo Bazán, Concepción Gimeno, Carmen de Burgos (Colombine), Isabel Oyarzábal and Carmen Eva Nelken (Magda Donato). All of them agreed on the idea that women have an innate predisposition for the practice of journalism, and that the press is a platform from which to educate other women. Their journalism is inspired by two primary patterns, the nineteenth-century chronicle, which originated in France, and the more modern interview and report approach, originating in the Englishspeaking world. In the practice of journalism the only limitations for women in Spain seemed to be the role of editor-in-chief of a daily newspaper and the report genre; both of which were controlled by men, while women were assigned to journalistic genres such as the chronicle and the interview, considered to be better suited to them.

KEYWORDS: woman journalist; report; chronicle; interview; Colombine; Magda Donato. 


\section{LAS PERIODISTAS ESPAÑOLAS PINTADAS POR SÍ MISMAS}

Cinco grandes periodistas españolas que vivieron entre los siglos XIX y XX dedicaron algunos de sus artículos y discursos a reflexionar sobre su profesión: Emilia Pardo Bazán, Concepción Gimeno, Carmen de Burgos, Isabel Oyarzábal y Carmen Eva Nelken. Cuatro de ellas fueron, además, directoras de revistas (Bussy, 2005), por lo que conocían muy bien el medio: Pardo Bazán lo fue de la Revista de Galicia (1880) (Pardo Bazán, 1880, ed. 1999) y el Nuevo Teatro Crítico (1891-1893), Gimeno dirigió La Ilustración de la Mujer (fundada en 1873) ${ }^{1}$, El Álbum de la Mujer (Méjico, 1883-1889) (Ramos Escandón, 2005) y El Álbum IberoAmericano, 1890-1910 (Chozas, 2005; Bianchi, 2008). Carmen de Burgos fundó en 1908 la Revista Crítica, que salió entre septiembre de este año y abril de 1909 (Núñez, 2005, pp. 216-225); Isabel Oyarzábal dirigió junto con su hermana Ana la revista La Dama (19071908), que se titularía posteriormente La Dama y la Vida Ilustrada, 1908-1911 (Bados Ciria, 2010).

Estas cinco escritoras colaboraron en buen número de publicaciones periódicas españolas y extranjeras; en el caso de Concepción Gimeno, Isabel Oyarzábal y Magda Donato fueron especialmente significativas sus contribuciones a la prensa mexicana; Concepción Gimeno creó y dirigió en México El Álbum de la Mujer; Isabel Oyarzábal colaboró en El Journalista y España Peregrina y Magda Donato en la revista Don Quijote y el diario Mañana. Pardo Bazán publicó numerosos artículos en el Diario de la Marina de La Habana y La Nación de Buenos Aires; Carmen de Burgos colaboró con el diario portugués O Mundo entre 1919 y 1921. Isabel Oyarzábal, además, trabajó para la agencia de noticias Laffan News Bureau, y fue corresponsal del The Standard y del Daily Herald en España (Quiles Faz, 2002). Dos de ellas ocuparon también un destacado lugar en los inicios de la radio: Carmen de Burgos y Magda Donato (Simón, 2012, p. 142 y pp. 146-147).

En el ejercicio del periodismo tres de ellas popularizaron seudónimos: Carmen de Burgos los de Colom$b_{\text {bine }}^{2}$, Perico el de los Palotes (Arroyo 2010), Raquel, Marianela, Claudine y Gabriel Luna, Isabel Oyarzábal el de Beatriz Galindo y Carmen Eva Nelken el de Magda Donato.

Fueron mujeres con una notoria proyección pública: escritoras, periodistas y conferenciantes, viajeras impenitentes, miembros de numerosas asociaciones en defensa de las más diversas causas y desempeñaron profesiones diversas con una importante presencia pública, además del periodismo: Carmen de Burgos era maestra, Magda Donato actriz, Isabel Oyarzábal diplomática y Pardo Bazán llegó a ser catedrático (Ezama 2012 a). Algunas de ellas mantuvieron un salón literario (Pardo Bazán, Gimeno, Burgos), como sus correligionarias Delphine de Girardin, Marie d’Agoult (seudónimo Daniel Stern), la condesa de Noailles o Juliette Adam (Heyden-Rynsch, 1998); precisamente uno de los asertos admitidos entre los investigadores es el del origen salonnière del periodismo (Thérenty, 2007, pp. 174-178), que ilustran muy bien las crónicas de Delphine de Girardin:

Lo curioso del caso es que la actividad gacetillesca tiene su origen en la mujer, pues fue en los salones famosos de otros tiempos donde se concibió el hoy robusto infante, el periódico, que empezó a adquirir forma real en las cartas privadas de aquella gloriosa época en las cuales se comentaban con travieso y sutil espíritu los acontecimientos mundanos y sociales.

Puede decirse que la primera rotativa llevaba la marca Madame Sevigné (Anónimo, 1928).

Y así parece corroborarlo el periódico francés $L a$ Fronde, ejemplo excepcional de periódico diario ${ }^{3}$, de intereses generales, dirigido por una mujer (Marguerite Durand) y redactado íntegramente por mujeres, de cuyo ambiente salonnier informa una crónica de Pardo Bazán de 1899 (Posada, 1899, pp. 33-140; Rabaut, 1996, pp. 46-47; Roberts, 1997). O la escuela inglesa de periodistas que bajo el nombre de Literary Salon and School of Journalism, Shorthand and Art for Women, dirige Florence Cartwright (Stuart, 1911, p. 445). Pero en el paso del salón dieciochesco al periódico se produce un cambio desde la conversation (elitista y formalizada) a la causerie (más familiar y sencilla) (Thérenty, 2007, p. 177).

La aparición y consolidación de la mujer como profesional del periodismo tiene mucho que ver con el desarrollo del feminismo, ya que muchas revistas y periódicos se crean como órganos de expresión del mismo, v.gr. el Journal des Femmes de Maria Martin (1881-1891)4 , la Revue Féministe (1895-1897) de Clotilde Dissard, la Revue des Femmes Ruses et des Femmes Françaises (1896-1897) de Olga de Bezobrazow, Le Féminisme Chrétien (1896-1899) de Marie Maugeret, La Femme de Sarah Monod (1879-1937) y Ster (1895-1897) de la polaca Paulina Kuczalska; muchas de las mujeres que dirigieron estos medios periodísticos fueron también cabezas visibles de asociaciones feministas, v.gr. Marie Pognon presidía la Liga francesa para el derecho de las mujeres, Mme. G. Vincent La Igualdad, Marie Szeliga-Loevy la Unión Universal 
de las mujeres y Marie Maugeret El Feminismo cristiano (Posada, 1899, pp. 137-138). No obstante, Blum (2002, pp. 219-220) sostiene que el movimiento feminista no encontró en las revistas su forma ideal de expresión, ya que las militantes más conocidas dieron a conocer sus ideas en los órganos de expresión masculinos, practicando así un feminismo de integración. Algo parecido defiende para el caso portugués Isabel Lousada (2012, p. 61), cuando afirma que "esta opçao pela imprensa generalista e de cariz regional debe ser tomada como mais um recurso a uma fonte privilegiada de encontro com as mulheres".

Pero, ya se trate del feminismo, de determinadas ideologías políticas (socialismo, republicanismo) o credos religiosos (cristianismo, protestantismo), incluso de la heterodoxia librepensadora ${ }^{5}$, lo cierto es que el compromiso es inherente al ejercicio del periodismo por parte de las mujeres.

\section{Las periodistas pintadas por sí mismas: historia y condición}

Pardo Bazán (1897) considera a la mujer periodista un producto del siglo XIX, sobre todo de su segunda mitad (Dorado, 2006) y cree que la mujer posee condiciones que la hacen apta para el trabajo periodístico:

Pronta y sagaz en ver o adivinar lo que no se ve; fina observadora del detalle menudo y del matiz imperceptible que presta a cada objeto su atractivo y su significación; vibrante para sentir, y fácil y rápida en expresar el sentimiento; concienzuda y exacta para el desempeño de la diaria tarea; fresca de imaginación y bien penetrada del criterio más corriente en la sociedad; compasiva y tierna ante la desgracia; apegada a lo corriente y con un sentido de la realidad que la aleja de las abstracciones, y la adhiere a la tierra y la coloca en el momento presente, por decirlo así, la mujer sirve divinamente para ese oficio literario, que consiste en recibir impresiones de la actualidad y devolverlas sin tardanza en forma agradable, clara y simpática a la mayoría de los lectores.

La prensa escrita por mujeres que mejor conoce es la francesa, entre cuyos nombres cita en primer lugar el de Séverine (seudónimo de Caroline Rémy), sobre el que volverá en una crónica de 1900, para añadir:

Las mujeres descuellan como cronistas periodísticos. Las redactoras de La Fronda, con Séverine a la cabeza, hacen primores en ese terreno, siguiendo la tradición de aquel célebre vizconde de Launay, que también era una mujer y que dejó un insuperable modelo de crónicas en sus folletines sema- nales de La Prensa ${ }^{6}$. Eran tan entretenidos, que los analizó Sainte-Beuve y los definió con palabras en las cuales encuentro las tablas de la ley de la crónica, el decálogo del cronista, para escribir el artículo "picante, raudo, alegre, paradójico, no siempre falso; en el cual se debe resbalar y no insistir, rozar a flor de epidermis, sorprender los caprichos y las manías sociales, tomar lo frívolo por lo serio y lo serio frívolamente, escribir como se habla en un salón, y disfrazar con el buen sentido la risa, y con el relampagueo de la frase la vacuidad del fondo" (Pardo Bazán, 1900).

Volviendo al texto de 1897, Pardo Bazán enumera entre las periodistas francesas a la señora de Rute (Mme. Ratazzi), "cuyas crónicas son la misma amenidad"7; la feminista y socialista de origen polaco Paule Mink (Adele Pauline Mekarska); Juliette Lamber -Juliette Adam- (directora de La Nouvelle Revue); Arsène Arus (seudónimo de la peruana Sara Oquendo, buena amiga de Pardo Bazán) y Arvède Barine (seudónimo de Mme. Charles Vincens). Menciona también a su amiga y corresponsal Guiomar Torreçao, editora del Almanach das Senhoras, que la portuguesa editó infatigablemente desde 1872 hasta su muerte en 1898 y que siguió publicándose luego hasta 1928 (Germano, 2010).

Concepción Gimeno (1900) presenta un panorama más cosmopolita que el de Pardo Bazán. Comienza sin embargo por la prensa francesa y por el emblemático diario La Fronde, entre cuyas redactoras cita a Marguerite Durand, Séverine, Bradamante (Mme. Constant), Emmy Fournier, Mathilde Pognon, Marie Léopold Lacour, G. Vincent, Claire de Pratz, Jane Catulle Mendes (Jean Nette), la pedagoga Pauline Kergomard, Clémence Royer y Daniel Lesueur (Jeanne Loiseau). Entre las contemporáneas, añade los nombres de Mme. Ratazzi, Désirée Langer -Georges Regnal- (Simple Revue), Olga de Bezobrazow, Marie Maugeret y Clotilde Dissard, la doctora Hélina Gaboriau (Le Bonheur au Foyer) y Sarah Monod. Pero además traza una breve historia de la prensa francesa desde 1789 hasta 1848, y luego hasta finales del siglo XIX, destacando en este último periodo Les Mouches et les Araignées de Paule Mink, La Femme dans la Famille et dans la Société de Louise Koppe, La Citoyenne de Hubertine Auclert, y el Bulletin de I'Union Universelle de Femmes, dirigido por Maria Szeliga-Loevy ${ }^{8}$.

De Alemania, Gimeno cita a las feministas y pedagogas Lina Morgenstern (German Housewives Journal) y Elena Lange (Die Frau). De Portugal a Enriqueta Pereira de Sousa, directora de Hymnos e Flores ${ }^{9}$, y de Italia a la directora de La Donna (1868-1890) Gual- 
berta Alaide Beccari. Entre las españolas menciona a Concepción Arenal (La Voz de la Caridad), Emilia Pardo Bazán (Nuevo Teatro Crítico), Faustina Sáez de Melgar (La Mujer), Josefa Pujol de Collado (El Parthenon), Ángela Grassi (El Correo de la Moda), la baronesa de Wilson (El Último Figurín), Sofía Tartilán (Las Hijas del Sol) ${ }^{10}$, Patrocinio de Biedma (Cádiz) y Belén Sárraga (La Conciencia Libre) $)^{11}$.

Tras este recorrido apresurado por la prensa de diversos países, Gimeno (1900) se detiene en algunos nombres propios: Étincelle (vicomtesse de Peyronny, baronne Double), Paulina Kuczalska-Reinschmidt, condesa Martel de Janville (Gyp), la feminista y socialista Citoyen Sorgue (seudónimo de Antoinette Cauvin), Séverine, Juliette Lamber y María Martin. De Étincelle escribe que es una elegante revistera que se ha consagrado al periodismo por "coquetería intelectual" (p. 567); menciona su sección "Carnet mondain" en Le Figaro, y sobre su estilo comenta: "Es la cronista ligera y amena, de estilo completamente moderno, delicado y fino, como los esmaltes de las porcelanas de Sèvres". Sobre Gyp señala que, además de ser prolífica escritora, representa también:

el verdadero tipo del cronista francés, satiriza sin herir, sus frases cáusticas no tienen veneno. Posee una vena cómica muy fina, que parece aumentar a medida que se desborda [...] Elegante, ingeniosa e intencionada, en el fondo de sus escritos encuéntrase siempre la ironía, pero una ironía amable. La condesa Martel es el filósofo de las cosas ligeras (Gimeno, 1900, p. 567).

Por otra parte, a Antoinette Cauvin, a la que le ha cabido el honor de ser "la primera mujer belga que ha sido admitida entre los periodistas de la prensa jurídica en los tribunales", la califica de "cronista brillante" (Ibid.). No escatima, en fin, elogios para Séverine y Juliette Lamber, apostillando sobre esta última:

Sus crónicas extranjeras han ejercido influencia en la política, contribuyendo a estrechar los lazos entre Francia y Rusia, lo cual ha demostrado una vez más que la mujer puede prestar servicios cívicos a la patria lo mismo que el hombre. Hábil periodista, no se le arranca nunca en la interview lo que no quiere decir (Ibid., p. 568).

Más allá del repertorio de nombres propios que ofrecen Pardo Bazán y Gimeno, hay que destacar la reflexión sobre el periodismo escrito por mujeres realizada por Colombine, que es el texto de una conferencia leída por su autora en la Unión Ibero-Americana de Madrid el 15 de junio de 1905. El objetivo de este discurso es el de subrayar la importante misión de la mujer en la prensa, una misión educadora, que ella misma trató de llevar a la práctica con sus crónicas en el Diario Universal y Heraldo de Madrid, entre otros periódicos ${ }^{12}$.

Comienza Carmen de Burgos su discurso reconociendo el papel activo desempeñado por la mujer en la prensa y situando a Francia al frente de este movimiento, con firmas como las de la condesa Anna de Noailles, Marie d' Agoult, Georges de Peyrebrune (seudónimo de Mathilde de Peyrebrune), Juliette Adam, Marcelle Tinayre, Mme. Alphonse Daudet (firma de Julia Allard), Jean Bertheroy (seudónimo de Berthe-Corinne Le Barillier), Jane Dieulafoy, Judith Gautier, Jeanne Marni (Jeanne Marie Françoise Marnière), Gyp, Jane Catulle Mendes y Clarisse Coignet, y sobre todo Séverine: "la verdadera encarnación del periodismo es Séverine, la cronista incomparable de El Figaro, que se ocupa de las cuestiones sociales y sostiene todas las campañas nobles en defensa de los derechos y de la justicia" (Ibid.) $)^{13}$. Se detiene también para hablar de La Fronde, que pone como ejemplo de que

las mujeres entienden tan bien como los hombres lo que pudiera llamarse la cocina de un periódico diario. Cocina en la que han de entrar en dosis bien combinadas la política interior y exterior, las informaciones de actualidad, los tribunales, las bellas artes y las noticias del reporterismo con los artículos sensacionales y de fondo, todo hábilmente aderezado para poderlo servir al público (Ibid. $)^{14}$.

Más allá de Francia, presta atención a periodistas de otros países como Italia, donde destaca a Matilde Serao ${ }^{15}$, y Portugal donde subraya la labor de Amalia Vaz de Carvalho y Claudia Campos, corresponsales de diarios del Brasil ${ }^{16}$, Alice Pestana (seudónimos Caiel, Cil) que colabora con el Diario de Lisboa, Alice Moderno (dirige la revista $A$ Folha en las Islas Azores) y Maria Olga Moraes Sarmento (directora de la revista Sociedade Futura).

A continuación se ocupa del periodismo en Estados Unidos, país en que las periodistas desempeñan todos los cargos, incluso el de reporteras sensacionalistas. Con todo, cree que el primer puesto en el periodismo femenino lo "merece con justicia Inglaterra." (Ibid.); ofrece datos sobre los ingresos de las periodistas inglesas y una lista de nombres: Emily Crawford (corresponsal en París del Daily News), Mrs. Alice Meynell ${ }^{17}$, Rachel Challice (redactora del Daily Express), Jeannette Jerome -Lady Randolph Churchill- (editora de The Anglo-Saxon Review), Flora Shaw -Lady Lugard $-{ }^{18}$, Mary Frances Billington ${ }^{19}$ y Sarah Tooley ${ }^{20}$. 
A esta perspectiva sobre el periodismo inglés escrito por mujeres añade que

desde hace un año las mujeres inglesas disponen de un periódico diario que venden a diez céntimos el número. Tiene seis páginas y se dirige particularmente a las mujeres instruidas que siempre ansían aprender algo nuevo. Este periódico promete ser el diario femenino de más porvenir, sin espíritu de partido y con carácter esencialmente práctico (lbid., p. 87) $)^{21}$.

Además, Florence Cartwright ha fundado una escuela de periodistas (a la que ya me he referido), y las escritoras inglesas se han unido para formar la Society of Women Journalists (1895), presidida por Lady Sarah Wilson, que "tiene por objeto sostenerse mutuamente, hacer avanzar la causa del periodismo, ayudar a las que empiezan y simplificar las dificultades del oficio" (Ibid).

Tras la revisión del periodismo anglosajón, Colombine pasa revista a la "América española", y cita varios nombres de mujeres célebres, de los cuales solo un puñado corresponden a periodistas: Soledad Acosta en Colombia, Lola Rodríguez de Tió en Puerto Rico (periodista de ocasión), Paca Corrales en Costa Rica, Carmen Brige en Venezuela, y Concepción Boloña Coralia- en Cuba22.

Para terminar este repaso a la historia del periodismo contemporáneo se detiene Carmen de Burgos en las periodistas y publicaciones españolas ${ }^{23}$. Menciona a Beatriz de Cienfuegos (La pensadora gaditana) y Carmen Silva (El Robespierre Español) ${ }^{24}$ como iniciadoras; luego hace una lista de revistas dirigidas por mujeres: El Correo de la Moda por Ángela Grassi y Joaquina Balmaseda, La Violeta por Faustina Sáez de Melgar; La Moda Elegante por Maria del Pilar Sinués (Sánchez Llama, 2000), La Caprichosa por la baronesa de Wilson, Nuevo Teatro Crítico de Emilia Pardo Bazán, El Amigo del Hogar de Ma del Pilar Contreras, y La Moda Práctica por María Guerrero. Vuelve a mencionar algunos nombres de mujeres que han dirigido revistas: Robustiana Armiño (Ecos del Auseva), Sofía Tartilán (La Ilustración de la Mujer), Rosario de Acuña ${ }^{25}$, Julia Codorníu (El Álbum del Tocador), Ana Solo de Zaldívar (El Amigo del Hogar), y Rosa Eguílaz (propietaria del periódico Para Todos). Sigue un listado de publicaciones editadas en Barcelona también dirigidas por mujeres: La Ilustración de la Mujer por Concepción Gimeno ${ }^{26}$, El Ángel del Hogar de Esmeralda Cervantes (Clotilde Cerdá y Bosch), El Parthenon de Josefina Pujol de Collado, El Sacerdocio de la Mujer de Esperanza Belmar, y Manos Blancas, suplemento de EI
Liberal de Barcelona dirigido por la Condesa del Castellá (Isabel María del Carmen de Castellví y Gordon). Y en otras provincias: Carolina de Soto dirigió Asta Regia (Jerez de la Frontera), Clemencia Larra El Laurel Jienense, Enriqueta Lozano de Vilches La Madre de Familia (Granada) y Patrocinio de Biedma la revista Cádiz. Añade que algunas escritoras han colaborado asiduamente en los grandes rotativos, como es el caso de Salomé Nuñez Topete ${ }^{27}$.

La alusión a los grandes diarios despierta en la oradora un sentimiento de gratitud para con Augusto Suárez de Figueroa, "el fundador del periodismo moderno en nuestra patria y el primero en abrir las puertas de la gran prensa a las mujeres españolas" (Colombine, 1905, p. 87); cuenta cómo en Diario Universal creó una sección diaria dedicada a las mujeres, "dando además a una mujer el carácter de redactora, que hasta entonces no habían tenido en los grandes rotativos" (Ibid.); esa mujer no es otra que la propia Carmen de Burgos. Por todo ello cree que cuantas periodistas trabajen en la prensa se lo deben en buena medida a Figueroa: "Él fue el fundador de la nueva carrera que abre el periodismo para la mujer en nuestro país" (Ibid., p. 88).

Distingue en su discurso Colombine entre las mujeres que cultivan todos los géneros y las periodistas, y afirma que la misión de estas últimas es muy distinta de la de aquellas; hace un repaso a las exigencias de la labor del periodismo y añade las que se les piden además a las mujeres que llevan a cabo dicha labor:

No faltan a la mujer ninguna de las condiciones necesarias para el periodismo y tiene además la sensibilidad exquisita que le hace fijarse con preferencia en lo que representa adelanto y cultura.

Mientras que el hombre se ve obligado a hacer la información política, el relato del crimen, la revista de los tribunales y la noticia de actualidad, la mujer, con libertad para escoger asunto, pues son aún raros los casos de reporterismo entre nosotros, se fija en los adelantos e instituciones benéficas que protegen a la mujer y al niño; recoge los dolores de los pequeños, de los humildes, de los afligidos, las tristezas de su corazón, las angustias de la existencia de un luchador modesto, las penas y el desaliento de los oprimidos, las tempestades que conducen un cerebro a la locura, a la desesperación o al suicidio; y para cada una de estas cosas tiene un aliento de consoladora ternura o un grito de justicia. [...]

Ella nos muestra los males y los defectos para curarlos y corregirlos (Ibíd., p. 88). 
Para cerrar su discurso vuelve a retomar su aserto inicial sobre la función educadora de la mujer a través de la prensa:

en esos articulitos para los niños [...] en las revistas de modas, en las recetas de higiene de la belleza, en el consejo de economía o en la regla de sociedad, educa la mujer dentro del periodismo [...] Y en esta obra educativa ejerce una influencia más directa sobre las otras mujeres (Ibid.).

Porque, sostiene Burgos, la mujer intelectual ha de ser la educadora de las otras mujeres, que poseen un entendimiento menos cultivado que el de los hombres. De este modo, los más importantes diarios españoles ponen su sección femenina en manos de mujer: Diario Universal ("Lecturas para la mujer" por Colombine), La Correspondencia de España ("Actualidades femeninas" por Raquel, Marianela), El País ("Carnet femenino" por Violeta -seudónimo de Consuelo Álvarez-), El Liberal ("Manos blancas" por la condesa del Castellá), El Globo ("Crónicas feministas" por Evangelina -Zoila Aurora Cáceres-), El Imparcial ("Femeninas" por Magda Donato), Heraldo de Madrid ("Femeninas" por Colombine), El Sol ("Páginas femeninas" y luego "La mujer, el niño y el hogar" por Maria Luz Morales).

De todo ello concluye que "no es España el país más atrasado en el periodismo femenino" (Ibid., p. 89). Y esgrime el orgullo de ser periodista: "creo y espero en su misión civilizadora, y estimo el título de periodista más que todos los honores que puedan poseerse en la tierra" (Ibid.) ${ }^{28}$.

Además de este documentado discurso, Carmen de Burgos dedicó tres artículos a las periodistas inglesas en los que reproduce prácticamente la misma información que en el discurso citado (Colombine, $1904 a$; 1904 c), aunque en el último (Colombine, 1907) añade dos nombres a la relación de periodistas: Humphrey Ward (seudónimo de Mary Augusta Ward) y Adelaide Belloc Lowndes.

La figura de la mujer reportera que Carmen de Burgos cita en su discurso de 1905 se materializa en una entrevista que le hizo en 1915 a la periodista portuguesa Virginia Quaresma, que comienza con esta afirmación: "Los grandes triunfos del periodismo moderno no son triunfos de literatos ni de cronistas; son triunfos de reporter $^{\prime 29}$. Y a esta modalidad de periodismo se dedica Virginia Quaresma, lo que sorprende a Colombine:

Hallar una mujer periodista de esa escuela y de un valor capaz de parangonarse con los mejores periodistas masculinos, en nuestra misma Península, confieso que fue para mí una sorpresa.
Entre todas las periodistas sudamericanas, francesas, italianas, alemanas y del norte de Europa que yo he conocido no encontré ninguna del valor, de la modernidad, del atrevimiento de la periodista portuguesa doña Virginia Quaresma; es verdaderamente original.

Carmen de Burgos la presenta como "una periodista de vocación", que con frecuencia declara "Yo he nacido reporter". Mujer de "rara instrucción, versada en humanidades, en filosofía; conocedora de varios idiomas, oradora y cronista notable"; considera Colombine que es el suyo un ejemplo "que prueba cuánto puede conseguir la mujer con su propio esfuerzo" ${ }^{30}$.

Quaresma confiesa en la entrevista que adquirió afición al periodismo leyendo Heraldo de Madrid, y que fue muy amiga de Luis Morote. Da cuenta de su vida periodística, empezando por el Journal da Noite, la revista Alma Femenina (que dirigió) y O’Seculo, para acabar con Manuel Guimaraes y otros compañeros que fundaron A Capital. Y declara, por último, que en su larga carrera como reportera no ha tropezado con envidias ni malevolencias.

Por los mismos años, la periodista Isabel Oyarzábal (Beatriz Galindo) escribió dos trabajos sobre la profesión periodística en la mujer, uno en 1917 y otro en 1919. En el primero establece una afinidad entre ambas:

Quizás de todos los campos abiertos a la actividad y a la energía femenina, ninguno esté tan en consonancia con las aptitudes y dones especiales de la mujer como el del periodismo. Ningún trabajo encaja mejor que este en su modo de ser, ni se amolda tan exactamente a su idiosincrasia, ni la ofrece las mismas garantías de éxito, siempre, claro está, que la mujer ponga en él toda la inmensa fuerza de su espíritu observador, de su intuición maravillosa, de su actividad mental y su fantasía, cosas indispensables para desempeñar este oficio, el más inquieto, arduo y atrayente de cuantos han evolucionado dentro de la complicada máquina de la vida moderna [...]

Por lo que tiene de sutil, de fugaz y de complejo es por lo que juzgo tan capaz de desempeñarlo a la mujer, sobre todo en lo que a ciertos terrenos de indagación, de información delicada y difícil se refiere (Galindo, 1917).

Señala Beatriz Galindo que casi todas las periodistas han comenzado su labor "dentro de los límites estrictamente femeninos", pero

a medida que se amplía el horizonte femenino y que la lectura exige lo que no exigiera antes, la pe- 
riodista aumenta también su actividad y produce crónicas de interés más extenso, informaciones de carácter educativo y artístico o se dedica a desentrañar y buscar la solución de aquellos problemas sociales que más afectan a la mujer.

Cita como exponentes a Salomé Nuñez Topete, Colombine, María de Perales ${ }^{31}$, María de Echarri ${ }^{32}$, Margarita Nelken y Matilde Muñoz $^{33}$, a las que tilda de "precursoras del periodismo femenino en España".

En su segundo artículo Galindo se ocupa de "La necesidad de una gran revista" (1918), ya que aunque existen en nuestro país muchas publicaciones femeninas,

no llegan a satisfacer, en grado ínfimo siquiera, las necesidades espirituales e intelectuales de esta [la mujer], ofreciéndole, como hacen muchas revistas femeninas del extranjero, aparte lo que para su misión en la vida pueda serle necesario, una información general de todo el movimiento social, político, artístico y literario del mundo.

Opina que siendo el periódico un medio rápido y eficaz para formar opinión y conciencia, es lamentable que las mujeres españolas no puedan contar con una publicación que satisfaga estos objetivos, revistas como The Queen, Femina, The Lady's Field, Harper's Bazaar, The Woman's y Home Journal,

repletas de información útil y recreativa a la par; verdaderas guías del movimiento mundial, en las que la mujer puede encontrar todo cuanto le interesa, desde la última novedad en hechuras de zapatos, hasta las críticas literarias y enseñanzas filosóficas de mayor trascendencia.

Cree que España tiene elementos suficientes para hacer una revista moderna, pero también un inconveniente: "Esta ñoñería de esas corrientes de insustancialidad y esos prejuicios que cercan al sexo femenino en nuestra patria".

Por último, la periodista Magda Donato dedicó dos artículos a reflexionar sobre la mujer y la prensa. El primero de ellos es de enero de 1918 (Bernard, 2009 $b, \mathrm{pp} .17-19)$ y en él afirma que el periodismo es la clase de literatura que más conviene a las mujeres ya que están mejor constituidas para él que los hombres:

Carecemos de las cualidades especulativas que para el periodismo son una inutilidad y hasta un estorbo, y, además tenemos todas las que le son necesarias. Así nosotras somos instrumentos igualmente admirables y fieles para el periodismo de ideas y para el periodismo de información. [...]
El verdadero periodismo, el periodismo verdaderamente periodístico, es el de información. Pocas mujeres todavía se han dedicado a él, por lo menos como debían hacerlo.

Cree, en fin, Nelken, que únicamente las mujeres pueden llevar al periodismo a su pleno desarrollo:

Solo las mujeres tienen bastante corazón para poner en el periodismo la dosis de humanitarismo desinteresado, del cual es susceptible; solo ellas tienen bastante constancia o testarudez para llevar su tarea a cabo, a través de todas las dificultades y de todas las amarguras; solo ellas tienen bastante valor y bastante serenidad para afrontar todas las luchas; solo ellas, en fin, son capaces de bastante pasión para encariñarse con su obra, y de bastante fe para, poniéndose a su nivel, y queriéndola, redimirla del cinismo periodístico, con el cual los hombres creen probar una superioridad.

En un artículo posterior, vuelve Donato sobre las periodistas (1920), dibujando tres tipos: el de la señorita aficionada, el de la intelectual y el de la profesional, siendo este último en el que se incluye la propia articulista. Señala Nelken que el número de las periodistas profesionales ha ido aumentando con los años, de modo que en el momento presente "cada redacción tiene, a modo de perrito de lujo, una redactora encargada de amenizar el texto" (Ibid., p. 16). Distingue únicamente dos categorías en el periodismo escrito por mujeres: modas y feminismo, categorías en las que la misma profesional alterna, utilizando como transición entre ambos las interviús de actrices y visitas a las obras benéficas. Y si las categorías son dos, las especies de profesionales son múltiples e infinitas:

A veces somos una verdadera chica de la prensa $[\ldots]$

A veces somos una señora casada y tenemos la ventaja de la cooperación de nuestro marido. [...]

A veces, somos una buena señora, inofensiva, pero atacada por el delirio de grandezas y la monomanía del heroísmo. [...]

A veces somos una socialista furibunda [...]

A veces somos una excelente católica [...]

A veces hacemos crítica de lo primero que nos viene a mano.

$\mathrm{Y}$ a veces, somos yo, sencillamente, y entonces... Entonces preferimos callar y no insistir, porque la modestia de las mujeres tiene límites y la de las periodistas está por nacer (Ibid.) 
Por último, en la entrevista que José Montero le hizo a Nelken en 1932 esta incide en lo que la mujer puede aportar al periodismo:

La incorporación de la mujer al periodismo significa -o puede significar- el acercamiento a determinados temas antes vedados o poco asequibles al hombre. Es innegable que hay asuntos, que hay zonas de interés o de la actualidad más a tono con el espíritu, la comprensión y la pluma de la mujer. La aportación de esta al periodismo equivaldrá, por tanto, a una mayor amplitud en el horizonte de los temas, a un enriquecimiento de la sensibilidad en la visión de las figuras y los hechos que la actualidad vaya brindando (Montero, 1932, p. 14).

\section{Para concluir}

De las cinco escritoras que he considerado, hay dos que poseen una conciencia de su profesión periodística mucho más acusada que el resto; me refiero a Carmen de Burgos y Carmen Eva Nelken. La primera, en una entrevista que le hizo González Fiol en 1922, se manifiesta plenamente consciente del lugar que ocupa en la historia del periodismo femenino español:

Sin vanidad puedo decir que así como a los reyes se les da un sobrenombre, a mí me cuadra el de Precursora en el periodismo; yo he sido la primera mujer española que ha celebrado interviews con políticos y con artistas... [...].

He sido la primera mujer que en España ha sido corresponsal de guerra, pues fui enviada a Marruecos por el Heraldo de Madrid... (Colombine en González Fiol, 1922, p. 20).

Por otra parte, la labor literaria de Magda Donato está estrechamente vinculada al periodismo, como reconoce la autora en entrevista con Montero Alonso:

Mi labor periodística o literaria fue hasta ahora por dos caminos: interviú y reportaje, por un lado; cuento infantil por otro... En realidad, lo que a mí me gustaba cuando empecé a escribir, era la novela. Pero ya sabe usted que el periodismo es una profesión en la que se entra con facilidad y de la que se sale con dificultad. Entré en una redacción, y el periodismo fue ya una labor de todos los días. La novela hubo de quedar, forzosamente, a un lado. Interviús, reportajes, cuentos para chicos... (Montero Alonso, 1932, p. 14).

Entre las periodistas españolas está bastante extendida la idea de que la mujer posee cualidades innatas para el ejercicio del periodismo, y de que la prensa es una tribuna desde la que educar a sus congéneres del mismo sexo. Sus modelos periodísticos de referencia son el francés (Pardo Bazán, Gimeno) y el anglosajón (Burgos, Oyarzábal, Nelken); y los géneros considerados más adecuados para las mujeres: la crónica decimonónica francesa y el reportaje y la interview, de origen anglosajón, y característicos del periodismo desde finales del siglo XIX.

El medio de expresión de las mujeres periodistas suele ser la revista, en la que ofician de colaboradoras, redactoras y directoras; Gimeno y Burgos tienen mucho interés en destacar, sobre todo, a las periodistas que fundaron y dirigieron revistas, como ellas mismas. Gimeno y Oyarzábal editaron revistas femeninas, en tanto que Pardo Bazán y Burgos optaron por publicaciones de interés más general, centradas en la literatura y en la cultura semita, respectivamente.

En España no aparecen mujeres como directoras de periódicos diarios en el siglo XIX y primer tercio del XX (excepción hecha de M.a Luz Morales, que dirigió La Vanguardia entre julio de 1936 y febrero de 1937), aunque sí colaboran habitualmente en sus páginas; panorama un tanto diferente del de países como Francia (La Fronde), Italia (II Giorno di Napoli) e Inglaterra (Daily Mirror).

Sin embargo hay una periodista española que se atreve a pergeñar el proyecto de un periódico diario propio: es Emilia Pardo Bazán en un artículo publicado en 1901, titulado "Mi periódico". La escritora coruñesa comienza por elegir un título corto: El No; prosigue luego por el artículo de fondo, que restringiría a una o dos veces por semana, porque "hay otras muchas cosas tan dignas de encabezar un diario como la política". Sería además el suyo un periódico de provincias, pero no por ello encerrado "en un localismo ni en un regionalismo enfadoso y estrecho. Un diario es una ventana abierta de par en par, no solo sobre la Península, sino sobre el mundo entero". Este diario prestaría una atención especial a Portugal y al Arte y las Letras, ya que afirma rotundamente, "Mi periódico es un educador. Reniego del que no lo sea". No desdeñaría las noticias sensacionales, porque "si es verídico bien podemos calificarlo de documento humano. Querer que el periódico diario no refleje la vida diaria, iperegrina ocurrencia!"; pero sí los asuntos de la vida privada. Le interesaría también conocer "la gestión de los negocios públicos, la administración". Tampoco excluiría "ni las crónicas de sociedad, que divierten a muchas y muchos, ni las recetitas, ni las modas, ni la economía doméstica, ni el alta y baja de los que viajan o están de días, ni ninguna menudencia amena y dulce". En cuanto al 
estilo "trataría de que se redactase el texto en el mejor castellano posible" y "evitaría las erratas".

Todas estas consideraciones evidencian lo sexuado de las rúbricas y los géneros periodísticos: las rúbricas políticas y diplomáticas están bajo la responsabilidad de los hombres, lo que concierne a la casa, la intimidad y lo mundano pertenece al ámbito de las mujeres; a los hombres se les adjudica lo excepcional, el acontecimiento, a las mujeres lo iterativo, lo banal y prosaico; a la esfera masculina el editorial político, que escapa a las mujeres, al igual que el reportaje:

De fait, le seul grand genre journalistique qui, durablement et explicitement reste ouvert aux femmes, et oú la supériorité féminine est même affirmée par certains, est la chronique. Cette spécificité tient d'abord au caractère centripète du genre tourné vers les intérieurs, la mondanité, les modes, les fêtes, tous domaines réservés aux femmes [...] En privilégiant causerie, bel esprit et conversation, la chronique s'affirme l'héritière de cette sociabilité feminine (Planté y Thérenty, 2009, p. 24).

Este modelo de periodismo sexuado se establece en los años 1830-1840 a partir de las crónicas de Delphine de Girardin; entre 1870 y 1880 un nuevo género periodístico, el reportaje, connotado a menudo como masculino, destrona poco a poco a la crónica. Pero tal polarización se rompe debido a la aparición de la gran reporter Séverine, y de La Fronde, un periódico diario en el que las mujeres hacen reportajes (Thérenty, 2007, p. 118). Con todo, el reportaje, a tenor de las investigaciones realizadas hasta el momento, parece ser poco frecuente entre las periodistas españolas, salvo excepciones como Magda Donato (2009 a y 2009 b) y Josefina Carabias (Ezama, 2012 b).
En cuanto a la entrevista, hay unanimidad en considerar a la mujer mejor dotada que el hombre para dicho trabajo periodístico. A guisa de ejemplo podrían aducirse las muchas que hicieron Carmen de Burgos (García Templado, 2010) o Carmen Eva Nelken; González Fiol reflexiona sobre lo que supone "entrevistar a una intervieweuse" (González Fiol, 1922, p. 19) y Montero Alonso se coloca en la misma tesitura cuando se trata de Nelken:

Magda Donato es de las contadas mujeres -están en los dedos de la mano- que hacen periodismo activo, vivo. Interviú, información. Combate de palabras con el hombre o la mujer que va destacando la actualidad. Apresar gestos, actitudes, pensamientos y opiniones en una charla de media hora. Proyectar después esa charla sobre la breve pantalla de las cuartillas (Montero Alonso, 1932, p. 13).

Y lo mismo ocurre en otras latitudes, v.gr. la periodista americana Elizabeth L. Banks dedica uno de los últimos capítulos de su autobiografía al género de la entrevista, y comienza:

It is one of my chief ambitions as a journalist to become a really excellent interviewer. That goal I have not yet reached, but it is one towards which I strive. Interviewing, or doing what in newspaper parlance is known as "personal write-ups", is, it seems to me, the most pleasant, interesting, and edifying branch of journalistic work that can be taken up by a woman. It throws her into contact with the great, the extraordinary and the interesting people of the world (Banks 1902, p. 287). 
1 La llustración de la Mujer se mantuvo hasta 1877, y estuvo dirigida, al menos desde 1875, por Sofía Tartilán; son escasos los testimonios que relacionan a Gimeno con esta revista, entre ellos su propia afirmación en La mujer española (1877), y algún anuncio esporádico, como el que he encontrado en El Federal Salmantino, el 15 de junio de 1873 (p. 4), en el que se anuncia en estos términos: "La llustración de la Mujer. Revista quincenal. Órgano de la orden de las Hijas del Sol. Educación física, intelectual y moral de la mujer. Caridad y beneficencia. Justicia. Protección mutua. Directora: Maria de la Concepción Gimeno. Los productos de las suscripciones de esta revista se destinarán a la creación de escuelas gratuitas para niñas pobres". Con Sofía Tartilán se anuncia como órgano de expresión de la Asociación benéfica de señoras La Estrella de los Pobres, pero con la misma finalidad. Como los números de la revista que se conservan corresponden a los años 1875-1877, no es posible saber hasta dónde llegó la vinculación de Concepción Gimeno con ella. La baronesa de Wilson fundó una revista titulada Las hijas del sol, órgano de la asociación, sociedad cultural femenina, instituto femenino o logia masónica del mismo nombre (fundada en 1872), que no sé si tiene que ver algo con la revista de Concepción Gimeno. Probablemente ambas pertenecían a la masonería, pero este es extremo que no he podido constatar porque, que yo sepa, nadie ha visto la publicación de la baronesa de Wilson ni los primeros años de la de Gimeno.

2 El seudónimo se lo sugirió Augusto Suárez de Figueroa, director del Diario Universal y comenzó a utilizarlo en las páginas de este periódico en 1903; antes que ella el cronista francés Henry Fouquier, fallecido en 1901, había hecho uso del mismo en sus colaboraciones para Gil Blas (Thérenty, 2007, p. 244).

3 La Fronde no tuvo siempre periodicidad diaria: hasta 1903 y luego solo ocasionalmente (Rabaut, 1996, pp. 80-81, p. 114 y pp. 126-129).

4 El Journal des Femmes se editó entre 1891 y 1910 como continuación de La Citoyenne (1881-1891) de Hubertine Auclert, cuya dirección había asumido Maria Martin en 1888.
5 No resultan infrecuentes las vinculaciones con la masonería entre las periodistas francesas: Clemence Royer creó junto con María Deraismes la logia Droit Humain en 1893 , a la que pertenecieron, entre otras, Mathilde y Marie Pognon y Louise Koppe. Hay menos casos documentados entre las españolas y se dan sobre todo en el siglo XX (Carmen de Burgos, Consuelo Berges, Matilde Muñoz, Hildegart); probablemente también lo fueran Concepción Gimeno y la baronesa de Wilson (véase n. 1).

6 Las periodistas españolas se refieren a ambas como cronistas; el vizconde de Launay (Delphine de Girardin) sí lo era ciertamente: fue la creadora del género con su sección "Courrier de Paris" de $L a$ Presse a partir de 1836 (Thérenty, 2007, pp. 241-246); pero a Séverine le cuadra mejor el calificativo de reportera, ya que su periodismo se sitúa en la fase moderna de evolución de la prensa, y sus artículos son redactados sobre el terreno y no en la mesa de redacción (Thérenty, 2009, p. 118). Ejemplo de cronista española fue Pardo Bazán (Ezama, 2007).

7 Maria Leticia Bonaparte-Wyse, por matrimonio sucesivamente Marie de Solms, Mme. Ratazzi y Mme. de Rute, era la editora de la Nouvelle Revue Internationale (Pardo Bazán, 1902).

8 "Esta notable dama [Szeliga-Loevy] ha sido la primera en el Comité del Sindicato de la Prensa Extranjera en París. Séverine y Mme. Latouche tienen puesto de honor en la Asociación de la Prensa parisiense, formada por hombres eminentes" (Gimeno, 1900, p. 567). L'Association des journalistes parisiens se fundó en 1885 y era una de las que agrupaban a los periodistas franceses (Avenel, 1895). En el Bulletin de l'Association des journalistes parisiens del 15 de abril de 1900 figuran Séverine (incorporada en 1895) y Augusta Latouche (afiliada en 1899), pero también Georges Regnal (afiliada en 1895), Marie de Veillechèze (admitida el 4 de enero de 1893), Désirée Carlier (incorporada en 1895), Mme. Louis Voltier (admitida el 31 de mayo de 1893), Mme. Jeanne Marni (admitida el 2 de marzo de 1898) y Mme. Jean-Bernard Passerieu (admitida en 1900). Por otra parte, existía un Syndicat des Journalistes socialistes, fundado en 1893, del que formaban parte Maria SzeligaLoevy, Mme. Duc-Quercy, Paule Mink y Hélène Sarrazin.
9 Sorprende una referencia tan escueta y tan lejana en el tiempo (1862) a la prensa portuguesa, habida cuenta las buenas relaciones de Concepción Gimeno con las escritoras portuguesas, entre ellas Guiomar Torreçao y Alice Pestana (Ezama, 2010, pp. 63-64 y pp. 70-71).

10 Desconozco si Sofía Tartilán dirigió esta revista; la que sí dirigió, al menos desde 1875, es La llustración de la Mujer, a la que he aludido en nota 1.

11 Sorprende encontrar en esta relación la figura de una librepensadora, uno de los principales miembros de la masonería femenina española; tal vez porque Gimeno mantuviera una cierta implicación con sectores del librepensamiento español, como a menudo se ha sugerido, más concretamente con la asociación de signo masónico "Las hijas del sol”, que presidía la condesa de Priegue (Pilar Amandi de Ozores) y en la que también estaban implicadas la baronesa de Wilson, Concepción Gimeno y hasta Concepción Arenal, según algunos sueltos periodísticos (v.gr. "Telegráficas", Diario Oficial de Avisos de Madrid, 21 de febrero de 1873, p. 4). Véase también n. 1.

12 La misión educadora de la prensa la habían señalado ya mucho antes periodistas como Larra y Clarín. Larra en "Un periódico nuevo" (La Revista Española, 26 de enero de 1835) afirma: "El periódico es una escuela indispensable, si no un síntoma, de la vida moderna", "habiendo periódicos, en primer lugar, no es necesario estudiar, porque a la larga ¿qué cosa hay que no enseñe un periódico?". Y Clarín en "Los periódicos" (El Imparcial, 8 de mayo de 1895): "El periódico en España es hoy una escuela de adultos".

13 Colombine dedicó un interesante artículo a Séverine en 1924, en el que se pone de manifiesto la admiración que sentía por la periodista francesa a la que tilda de: "gran maestra de periodistas. Pocas personas han sabido escribir como ella para la prensa. Lo ha reunido todo: gracia, valentía, decisión, soltura, oportunidad y un estilo brillante, maravillosamente limpio y claro. No hay ni un solo artículo de Séverine en el que ella no haya puesto su alma toda. Su pluma escribe siempre vibrante de entusiasmo, movida más por el corazón que por la mano, en defensa de causas nobles y humanitarias" (Colombine 1924, p. 16). 
14 La expresión la cocina del periódico es de origen francés (Therenty, 2007, pp. 82-86); no se encuentra en la prensa española por esos años.

15 Serao es considerada la mejor periodista italiana: fue la primera mujer que trabajó como redactora de prensa en los años 80; fundó y dirigió algunos diarios: junto con su marido /l Corriere di Roma (1885) e II Mattino (1892), y luego ella sola I/ Giorno di Napoli (1904), que dirigió hasta su muerte. Carmen de Burgos (1927) dice que la conoció cuando dirigía /l Mattino en Nápoles, y afirma que han estado "unidas por una gran amistad durante muchos años".

16 Vaz de Carvalho colaboró con el brasileño Jornal do Comércio.

17 Meynell publicó en varios periódicos ejerciendo la crítica literaria; a través de sus artículos construye su propio status literario y rechaza adscribirse a cualquier forma de tradición literaria femenina, distanciándose de este modo de las mujeres contemporáneas, y elaborando su identidad literaria dentro de la prensa (Gray, 2012, pp. 71-90).

18 Shaw colaboró con varios periódicos, pero fue además la editora colonial del The Times de Londres, periódico para el que trabajó como corresponsal en Sudáfrica, Australia y Canadá, entre otros países; su labor periodística fue un medio de participar en la política, a mostrar su entusiasmo por la expansión imperial y por el desarrollo económico colonial (Helly, 2012, pp. 110-128).

19 Billington fue redactora del Daily Telegraph para el cual realizó, entre otros trabajos, una serie de reportajes sobre la mujer en la India que se publicarían en 1895 con el título de Women in India; en 1897 se hizo cargo de la dirección del Departamento de la Mujer del Daily Telegraph, cargo que ocupó hasta su muerte.

20 Tooley destacó en el arte de la entrevista, que ejerció en revistas como Woman at Home, Woman's Signal y Young Woman; la periodista opinaba que las mujeres estaban especialmente capacitadas para este género (Doughty, 2012, pp. 165-181).

21 Es el Daily Mirror, fundado por Alfred Harmsworth el 2 de noviembre de 1903, empresa periodística que constituyó un fracaso, por lo que su propietario decidió, en enero de 1904, cambiar la línea editorial del periódico y despidió a todas las redactoras; su primera directora fue Mary Howarth.

22 Esta relación probablemente sea de acarreo; el 30 de abril de 1905 Jesús Pando y Valle, secretario de la Unión Iberoamericana, había publicado en la revista Unión Iberoamericana un artículo titulado "La mujer en la Unión IberoAmericana", en el que reproduce un listado prácticamente igual a este, con algún nombre más. El único que añade Burgos es el de Coralia, colaboradora del diario habanero La Discusión. En un artículo anterior (Colombine 1904 b) citaba también a Ferina Sierra, hija de Coralia, que acababa de iniciarse en el periodismo.

23 Salvo algún añadido, este listado de periodistas españolas coincide con el que proporciona Criado y Domínguez, 1889: 49-53.

24 El ejemplo de Carmen Silva no cayó en el olvido; ya a finales del siglo XIX (desde los años 80) la reina de Rumanía, Elizabeth de Wied, había adoptado como seudónimo el nombre de Carmen Sylva, al que recurrió más tarde la escritora portuguesa Claudia de Campos.

25 Ignoro qué revista dirigió Rosario de Acuña.

26 Esta revista se editó en Madrid. Entre 1883 y 1887 sí se editó en Barcelona otra revista con el mismo título, cuyo propietario era Pedro Rigual Alayo, su representante en Madrid Josefa Pujol de Collado y en París Faustina Sáez de Melgar; tuvo tanto colaboradores masculinos como femeninos, entre estos últimos Josefa Pujol, Esmeralda Cervantes, Emilia Calé y Dolors Moncerdà.
27 Salomé Núñez publicó asiduamente en la prensa española crónicas de moda y artículos literarios; también dio a la luz trabajos periodísticos en La Nación de Buenos Aires y en el Diario de la Marina de La Habana; fue una de las primeras mujeres que formó parte de la Asociación de la Prensa de Madrid (Hernando, 2010).

28 Parecido orgullo expresa Maria Luz Morales: "sobre esta tierra que pisamos yo no he debido querer, no he querido ser otra cosa que esto que humildemente soy: simple y llanamente, periodista" (Morales, 1973, p. 9).

29 El anglicismo reporter se usó durante mucho tiempo en la prensa; la voz española reportero entró por primera vez en el DRAE en su edición de 1899 en el sentido de "Dícese del que lleva reportes o noticias" (en este sentido aparece utilizado en la prensa del XVIII), pero no es sino en 1936 cuando se admite la acepción: "Dícese del periodista que se dedica a los reportes o noticias".

30 Quaresma es un ejemplo de escritora comprometida, que utiliza el periodismo para defender diversas causas: el feminismo, el pacifismo, el rechazo de la violencia contra la mujer, y en general, los derechos humanos (Lousada, 2010).

31 Perales fue traductora y periodista: colaboró en Blanco y Negro, La Dama y la Vida Ilustrada, La Acción y otros medios.

32 Escritora, periodista y oradora, católica militante, colaboradora de Acción Católica e impulsora del primer Sindicato Femenino Católico, Echarri fue una mujer comprometida con la causa femenina y con la del obrero y encontró en la prensa el mejor medio de defenderlas (Aguilera y Lizárraga, 2010: 46-52).

33 Matilde Muñoz fue una periodista infatigable; empezó colaborando en $E I$ Imparcial y participó luego en muchos otros medios ( $A B C$, Mujer, Crónica); fue también una de las pioneras de la radio en España (Simón, 2012, pp. 141-144). 
Anónimo (1928). "Las mujeres periodistas". El Imparcial. Suplemento de Modas, 18 de octubre de 1928, p. 12.

Aguilera Sastre, J. y Lizárraga Vizcarra, I. (2010). De Madrid a Ginebra. El feminismo español y el VIII Congreso de la Alianza Internacional para el Sufragio de la Mujer. Barcelona: Icaria.

Arroyo Almaraz, A. (2010). "Crítica y difusión literarias por Perico el de los Palotes". Arbor, CLXXXVI, extra junio 2010, pp. 115-123.

Avenel, H. (1895). Le monde des journaux en 1895. Paris: Ancienne Maison Quantin.

Bados Ciria, C. (2010). "Isabel Oyarzábal Smith, editora y redactora: La Dama y La Dama y la Vida Ilustrada (1907. 1911)". En Bernard, M. y Rota, Y. (eds.), En prensa. Escritoras y periodistas en España (1900-1939). Bérgamo: Bérgamo University Press, pp. 15-43.

Banks, E.L. (1902). The autobiograpy of a newspaper girl. London: Methuen \& Co.

Bermard, M. (ed.) (2009 a). "Introducción". En Donato, Magda. Cómo vive la mujer en España. Sevilla: Arcibel Editores, pp. 3-34.

Bermard, M. (ed.) (2009 b). "Introducción". En Donato, Magda. Reportajes. Sevilla: Renacimiento, pp. 7-65.

Bianchi, Marina (2008). "Los artículos «a lo femenino» de María de la Concepción Gimeno de Flaquer". En Bernard, M.; Chierichetti, L.; González de Sande, M. y Rota, I. (eds.), Papel de mujeres. Mujeres de papel. Periodismo y comunicación del siglo XIX a nuestros días. Bergamo: Sestante Edizioni, pp. 21-49.

Blum, F. (2002). «Revues féminines, revues féministes». En Pluet-Despatin, J.; Leymarie, M. y Mollier, J.Y. (eds.), La Belle Époque des revues 1880-1914. Paris : Éditions de L'IMEC, pp. 211-212.

Bulletin de l'Association des journalistes parisiens (1900), no 15, 15 avril 1900.

Bussy Genevois, D. (2005). “La función de directora en los periódicos femeninos (1862-1936) o la "sublime misión»". En AA.VV. Prensa, impresos, lectura en el mundo hispánico contemporáneo. Homenaje a Jean-François Botrel. PILAR: Université Michel de Montaigne Bordeaux 3, pp. 193-206.

Chozas Ruiz-Belloso, D. (2005). "La mujer según el Álbum Ibero-Americano (1890 -1891) de Concepción Gimeno de Flaquer". Espéculo, no 29.
Colombine (1904a). "Actualidades femeninas. Mujeres periodistas en Inglaterra". La Correspondencia de España, 26 de enero de 1904, p. 6.

Colombine (1904b). "El periodismo femenino en Cuba". Diario Universal, 23 de julio de 1904, p. 1.

Colombine (1904c). "Actualidades femeninas. Periodistas inglesas". La Correspondencia de España, 25 de septiembre de 1904, p. 2.

Colombine (1905). "Misión social de la mujer en el periodismo". Unión IberoAmericana, 31 de diciembre de 1905, pp. 85-89.

Colombine (1907). "Femeninas. Periodistas inglesas". Heraldo de Madrid, 16 de febrero de 1907, p. 1.

Colombine (1915). "Femeninas. La gran re porter". Heraldo de Madrid, 30 de septiembre de 1915, p. 4.

Colombine (1924). "Mundo sefardita. La gran sulamita Séverine". Revista de la Raza, agosto-septiembre de 1924, pp. 113-114.

Colombine (1927). "Matilde Serao". La Esfera, 13 de agosto de 1927, p. 4.

Criado y Domínguez, J.P. (1889). Literatas españolas del siglo XIX. Madrid: Imprenta de Antonio Pérez Dubrull.

Donato, Magda (1918). "La mujer y el periodismo". El Imparcial, 13 de enero de 1918 , p. 3.

Donato, Magda (1920). "Al margen del feminismo. Nosotras las periodistas". España, 23 de octubre de 1920, pp. 15-16.

Donato, Magda (2009a). Cómo vive la mujer en España (ed. de Margherita Bernard). Sevilla: Arcibel Editores.

Donato, Magda (2009b). Reportajes (ed. de Margherita Bernard). Sevilla: Renacimiento.

Dorado, C. (2006). Emilia Pardo Bazán. Periodista de hoy. Madrid: Asociación de la Prensa de Madrid.

Doughty, T. (2012). “Representing the Professional Woman: The Celebrity Interviewing of Sarah Tooley". En Gray, E. (ed.). Women in Journalism at the Fin de Siècle. Making a Name for Herself. New York: Palgrave Macmillan, pp. 165-181.

Ezama Gil, Á. (2007). “Emilia Pardo Bazán revistera de salones: teoría y praxis de la crónica”. En González Herrán, J.M.; Patiño, C. y Penas, E. (eds.). III Simposio
Emilia Pardo Bazán: el periodismo. A Coruña: Fundación CaixaGalicia, pp. 233-259.

Ezama Gil, Á. (2010). "La Unión Ibérica de escritoras entre los siglos XIX y XX". Estudios Portugueses. Revista de Filología Portuguesa, 10, pp. 57-78.

Ezama Gil, Á. (2012a). "La vocación pedagógica de Emilia Pardo Bazán". Moenia, vol. 18 , pp. 417-437

Ezama Gil, Á. (2012b). "Los comienzos periodísticos de una reportera española: las colaboraciones de Josefina Carabias en La Voz (1932-1935)", El Argonauta Español, 9.

Galindo, Beatriz (1917). "Presente y porvenir de la mujer en España. La periodista". El Día, 14 de abril de 1917, p. 5.

Galindo, Beatriz (1918). "Para las damas. La necesidad de una gran revista". El Sol, 18 de febrero de 1918, p. 2.

García Templado, J. (2010). «Confidencias de artistas, de Carmen de Burgos». Arbor, CLXXXVI, pp. 125-138. http://dx.doi. org/10.3989/arbor.2010.extrajunion3015

Germano de Oliveira Romariz, A. de (2010). O Almanaque de Lembranças LusoBrasileiro: Um ensaio para um projecto mayor?. Universidad de Lisboa. Recuperado de http://hdl.handle.net/ 10451/5145.

Gimeno, C. (1900). "Mujeres contemporáneas". El Álbum Ibero-Americano, 30 de diciembre de 1900, pp. 566-568.

González Fiol, E. (1922). "Domadores del éxito. Carmen de Burgos (Colombine)". La Esfera, 24 de junio de 1922, pp. 19-20.

Gray, F.E. (2012). "Alice Meynell, Literary Reviewing, and the Cultivation of Scorn". En Gray, E. (ed.). Women in Journalism at the Fin de Siècle. Making a Name for Herself. New York: Palgrave Macmillan, pp. 71-90.

Helly, D.O. (2012). "Flora Shaw and the Times: Becoming a Journalist". En Gray, E. (ed.). Women in Journalism at the Fin de Siècle. Making a Name for Herself. New York: Palgrave Macmillan, pp. 110-128.

Hernando, B.M. (2010). "Carmen de Burgos, the $A P M$ and those astonishing girls of the 98". Arbor, CLXXXVI, pp. 3741. http://dx.doi.org/10.3989/arbor.2010. extrajunion3004

Heyden-Rynsch, V. von (1998). Los salones europeos. Las cimas de una cultura 
femenina desaparecida. Barcelona: Península.

Lousada, I. (2010). "Feminismo en la voz de una periodista feminista. Virgínia Quaresma". XV Coloquio Internacional de AEIHM: Mujeres e historia. Diálogos entre España y América Latina. Recuperado de http://hdl.handle. net/10362/4362

Lousada, I. (2012). “Elos de progresso social e científico: contributo para a História das Mulheres Cientistas em Portugal". En Women, Science and Globalization: What's up?. Lisboa: Amonet, pp. $57-$ 85. Recuperado de http://run.unl.pt/ bitstream/10362/8389/2/Amonet-Isabel\%20Lousada\%20p65.pdf

Montero Alonso, J. (1932). “Magda Donato, actriz, periodista y creadora de cuentos infantiles". Crónica, 29 de mayo de 1932, pp. 13-14.

Morales, M.L. (1973). Alguien a quien conocí. Barcelona: Juventud.

Núñez, C. (2005). Carmen de Burgos Colombine en la Edad de Plata de la literatura española. Sevilla: Fundación José Manuel Lara.

Pando y Valle, J. (1905). "La mujer en la Unión Ibero-Americana". Unión IberoAmericana, 30 de abril de 1905, pp. 6-8.

Pardo Bazán, E. (1880, ed. 1999), La Revista de Galicia de Emilia Pardo Bazán (estudio y edición de Ana María Freire López). La Coruña: Fundación Pedro Barrié de la Maza.
Pardo Bazán, E. (1897). "La mujer periodista". La Correspondencia Alicantina, 22 de octubre de 1897, p. 1.

Pardo Bazán, E. (1899). "La vida contemporánea". La llustración Artística, 29 de mayo de 1899, p. 346

Pardo Bazán, E. (1900). “La vida contemporánea. Crónicas y cuadros”. La Ilustración Artística, 26 de febrero de 1900, p. 138.

Pardo Bazán, E. (1901). "Mi periódico". El Noroeste, 30 de octubre de 1901, p. 1

Pardo Bazán, E. (1902). "La vida contemporánea". La Ilustración Artística, 7 de abril de 1902, p. 234.

Planté, C. y Thérenty, M.E. (2009). “Masculin/Féminin dans la presse du XIXe siècle. Le genre de la critique". En Andrin, M. et al. (eds.). Femmes et critique(s). Lettres, Arts, Cinéma. Namur: Presses Universitaires de Namur, pp. 14-28.

Posada, A. (1899, ed. 1994). Feminismo (edición de Oliva Blanco). Madrid: Cátedra.

Quiles Faz, A. (2002). "Periodismo y mujer: Isabel Oyarzábal y El Sol de Madrid (1917-1919)", En Gómez Yebra, A. (ed.). Patrimonio literario andaluz (vol. II). Málaga: Fundación Unicaja, pp. 111132.

Rabaut, J. (1996), Marguerite Durand (1864-1936). "La Fronde" feministe ou "Le Temps" en jupons, Paris: L’Harmattan.
Ramos Escandón, C. (2005). “Género e identidad femenina y nacional en $E I$ Álbum de la Mujer de Concepción Gimeno de Flaquer". En Clark, B. y Speckman, E. (eds.). La república de las letras. Asomos a la cultura escrita del México decimonónico (vol. II: Periódicos decimonónicos y otros impresos). México: Universidad Nacional Autónoma de México, pp. 195-208.

Roberts, M.L. (1997). “Copie subversive: le journalisme féministe en France à la fin du siècle dernier". Clio. Histoire, femmes et sociétés, 6, pp. 230-247. Recuperado de http://clio.revues.org/390

Sánchez Llama, Í. (2000). Galería de escritoras isabelinas. La prensa periódica entre 1833 y 1895. Madrid: Cátedra.

Simón Palmer, C. (2012). "Imagen sonora: escritoras en los inicios de la radio". En Vilches de Frutos, F. y Nieva de la Paz, P. (eds.). Imágenes femeninas en la literatura y las artes escénicas (siglos XX y $X X I)$, Philadelphia: Society of Spanish and Spanish-American Studies, pp. 135-150.

Stuart, B. (1911). Literary Yearbook and Bookman's Directory (vol. XV). London: Rouletdge and Sons.

Thérenty, M.E. (2007). La Littérature au quotidien. Poétiques journalistiques au XIX siècle. Paris: Éditions du Seuil.

Thérenty, M.E. (2009). "La chronique et le reportage: du "genre» (gender) des genres journalistiques". Études Littéraires, vol. 40, no 3, pp. 115-125. 